\title{
Understanding Breast Cancer Knowledge and Barriers to Treatment Adherence: A Qualitative Study Among Breast Cancer Survivors
}

\author{
Rachel A. Freedman, ${ }^{1, *}$ Anna C. Revette, ${ }^{2}$ Dawn L. Hershman, ${ }^{3}$ Kathryn Silva, ${ }^{1}$ Nora J. Sporn, ${ }^{2,4}$
} Joshua J. Gagne, ${ }^{2}$ Elena M. Kouri, ${ }^{5}$ and Nancy L. Keating ${ }^{5,6}$

\begin{abstract}
Disparities in breast cancer treatment receipt are common and multifactorial. Data are limited on how knowledge about one's breast cancer and understanding treatment rationales may impact treatment completion. In this qualitative analysis, we explored barriers to care with a focus on knowledge. We conducted 18 in-depth interviews with women from diverse socioeconomic backgrounds who were treated at Dana-Farber Cancer Institute $(n=12$; Boston, MA) and Columbia University Medical Center ( $n=6$; New York, NY) and had undergone neo/adjuvant breast cancer treatment within the prior 3 years. Interviews focused on treatments received, adherence, barriers experienced, and questions related to breast cancer knowledge and treatment rationales. We analyzed transcribed interview recordings in NVivo using a two-stage coding process that allowed for both preconfigured and emergent themes. Answers for breast cancer knowledge were confirmed using medical records. In our analysis, over one-third of women reported incomplete therapy, including never initiating treatment, stopping treatment prematurely, or missing/delaying treatments due to logistical reasons (childcare, transportation) or patient preferences. Others reported treatment modifications because of provider recommendations. Nearly all women were able to accurately describe the rationale for recommended treatments. Among 17 women for whom medical records were available, women correctly reported $18-71 \%$ of their tumor characteristics; incorrect reporting was not consistently associated with treatment incompletion. In conclusion, logistical issues and patient preferences were the main reasons for incomplete therapy in our study. Understanding of treatment rationale was high, but breast cancer knowledge was variable. Further assessment of how knowledge may impact cancer care is warranted.
\end{abstract}

Keywords: adherence; barriers; breast cancer; disparities

\section{Introduction}

Although survival rates for women with breast cancer have improved over time, ${ }^{1}$ there are several subgroups of women, including minority women, those of lower socioeconomic status (SES), ${ }^{2-5}$ and the youngest and oldest patients, ${ }^{6-8}$ who all have a significantly higher risk of dying from their disease. Among the multiple factors contributing to these mortality differences, adherence to effective treatments (including initiation and completion) plays a critical role, although many questions remain unanswered regarding why differences exist and how to improve treatment receipt and completion.

Past research provides some evidence that general cancer knowledge may play a role in outcomes and receipt of treatment for some women. ${ }^{9-12}$ Furthermore, specific knowledge about one's own breast cancer with regard to her staging and cancer subtype is poor overall and is worse for black and Hispanic versus

${ }^{1}$ Department of Medical Oncology, Dana-Farber Cancer Institute, Boston, Massachusetts.

${ }^{2}$ Survey and Data Management Core, Dana-Farber Cancer Institute, Boston, Massachusetts.

${ }^{3}$ Department of Medicine, Columbia University College of Physicians and Surgeons, New York, New York.

${ }^{4}$ Department of Community Health Sciences, Boston University School of Public Health, Boston, Massachusetts.

${ }^{5}$ Department of Health Care Policy, Harvard Medical School, Boston, Massachusetts.

${ }^{6}$ Division of General Internal Medicine, Brigham and Women's Hospital, Boston, Massachusetts.

*Address correspondence to: Rachel A. Freedman, MD, MPH, Department of Medical Oncology, Dana-Farber Cancer Institute, 450 Brookline Avenue, Boston, MA 02215, E-mail: rafreedman@partners.org

(c) Rachel A. Freedman et al. 2017; Published by Mary Ann Liebert, Inc. This is an Open Access article distributed under the terms of the Creative Commons Attribution License, which permits unrestricted use, distribution, and reproduction in any medium, provided the original work is properly cited. 
white women, as well as those with lower SES and older age. ${ }^{9}$ Some evidence suggests that having poor knowledge about one's cancer is associated with lower initiation rates of adjuvant breast cancer care, although this relationship is not well understood, ${ }^{13}$ and the impact on treatment completion or longer term adherence ${ }^{14}$ has not been assessed. A deeper understanding of how and why knowledge is associated with care may provide an opportunity to design interventions that can address this mutable factor.

In this study, to inform development of a large-scale survey, we conducted in-depth one-on-one telephone interviews with 18 breast cancer patients to explore potential barriers to treatment completion and hormonal therapy completion with a focus on breast cancer knowledge, understanding rationales for treatment, and how these factors may influence treatment receipt.

\section{Materials and Methods}

Study design, setting, participants

We recruited patients treated at Dana-Farber Cancer Institute (DFCI, Boston, MA) and Columbia University Medical Center (CUMC, New York, NY) with a recent history of breast cancer. We specifically sought to include a racially/ethnically and socioeconomically diverse sample. For DFCI-treated patients, flyers were posted in the breast oncology clinic to advertise the study. We also emailed breast oncology physicians/nurse practitioners and social workers to request referrals for patients who may be interested in participating, targeting those with stage I-III breast cancer diagnosed $\leq 3$ years who experienced challenges with treatment/stopped treatment prematurely. The study coordinator explained the nature of the research by telephone to those referred by providers and to any woman who called the number posted on flyers. For CUMC-treated patients, women with stage I-III breast cancer diagnosed $\leq 3$ years who had agreed to be contacted for future research and who provided an email address $(n=82)$ were sent an email with the same information as the DFCI flyer and were invited to contact the study team if they were interested. All flyers and emails were provided in English and Spanish to attract a diverse participant mix. We intended for up to 25 patients to participate, although we stopped recruitment when our analysis suggested thematic saturation. Interested patients were scheduled for a single 30-45-min phone interview with trained Qualitative Research Specialists in the Data-Technologies Research Core of Dana-Farber/ Harvard Cancer Center. This study was approved by the DFCI Institutional Review Board.

\section{Interviews}

After obtaining verbal consent, the interviewer asked a series of open- and closed-ended questions following a semistructured qualitative Interview Guide (Supplementary Data). We obtained information on neo/adjuvant treatment recommendations, goals, and treatment receipt, using questions such as, "Did your doctor or clinical team explain to you the goals of chemotherapy in treating your cancer? If so, what are they?," "Did you have any problems with the chemotherapy?" "Did you ever miss any treatments or have to have treatments cancelled? Why?" To assess knowledge, we included questions about one's tumor such as: "Was your cancer sensitive to estrogen, also known as estrogen receptor (ER)positive?" and "What was your cancer stage?" $\mathrm{We}$ also captured basic demographic information (age, education, difficulty paying bills). All interviews were tape recorded and professionally transcribed. After completion of the interview, women were mailed a $\$ 50$ gift card.

\section{Data analysis}

The primary goal of this study was to understand the challenges women faced with treatment initiation and completion throughout the entire course of their cancerdirected treatment, including surgery and adjuvant radiation, chemotherapy, and hormonal therapy. Specifically, we examined (1) reasons for incompletion of recommended treatments, (2) breast cancer knowledge and under standing of treatment rationales, and (3) whether knowledge may have influenced treatment receipt. Sociodemographic information from surveys was tabulated for study participants. For the 17 women with medical records available, we verified the accuracy of patientreported cancer stage, grade, and subtype.

We analyzed and summarized the transcribed data according to standard comprehensive, thematic qualitative analysis methods. The analytic approach involved a two-stage coding process and included both prefigured and emergent codes. ${ }^{15}$ Initial coding was primarily descriptive, with questions from the interview guide serving as the framework for the prefigured coding structure. With an orientation toward framework analysis, ${ }^{16,17}$ a more inductive approach was utilized in the second phase of coding. Categories that emerged from the data formed the broader thematic framework, which was then applied to all interview transcripts. These methods were validated by a $\mathrm{PhD}$ trained sociologist and enhanced using N'Vivo ethnographic data management software (QSR International) that uses an organizer indexing system for coding, categorizing, searching, retrieving, 
attaching analytical memos, and creating conceptual relationship networks in taxonomically coded textual data.

\section{Results}

Study participants

We interviewed 18 breast cancer patients (12 DFCI, 6 CUMC) during July 7, 2015-July 15, 2016 who were diagnosed between November 1, 2011 and November 1, 2015. The average interview duration was $31 \mathrm{~min}$ (range 18$74 \mathrm{~min}$ ); one interview was conducted in Spanish. Participant characteristics (at the time of interviews) are shown in Table 1. Participants had a median age of 52.5 (range 36-87 years). Approximately $22 \%$ were black or Hispanic, 33\% had less than a college degree, and 33\% reported some level of financial stress ("enough money for paying bills but only with cutting back" or "having difficulty paying bills"). Thirteen women were still receiving cancer-directed treatment, 6 of whom were taking hormonal therapy, 4 of whom were receiving chemotherapy (2 for recurrent disease), and three reported being on multiple treatments ( 2 receiving trastuzumab and/or pertuzumab and 1 receiving hormonal therapy and palbociclib on a clinical trial).

\section{Reasons for treatment nonadherence}

Overall, 9 participants reported some degree of treatment incompletion, including noninitiation, early cessation, or $\geq 1$ missed treatment and 7 of these 9 women (38.9\% of overall sample) reported not starting, stopping, or missing treatments because of reasons other than their provider stopping treatment for toxicity (3 of 7 reported difficulty paying bills). Two additional participants had individual circumstances (cancer metastasized, desire for pregnancy) that resulted in their stopping hormonal treatment (Table 2). Side effects associated with treatments emerged as the key factor for participants who reported missing or stopping treatment, some under the guidance and support of their clinical team. Transportation issues were also identified as a barrier to completing treatments, and even for participants who completed all of their treatments, transportation was still often a concern. Further information regarding specific incomplete treatments is described in more detail below.

Treatments received, problems encountered, understanding of treatment rationales

Surgery. Seventeen of the 18 participants reported undergoing surgery for their cancers (9 lumpectomy, 8 mastectomy [of which 3 were bilateral mastectomies]);
Table 1. Participant Characteristics $(N=18)$

\begin{tabular}{|c|c|}
\hline Characteristics & $N(\%)$ \\
\hline Age (median, range) & 52.5 years $(36-87)$ \\
\hline \multicolumn{2}{|l|}{ Race/ethnicity (self-identified) } \\
\hline Non-Hispanic white & $13(72)$ \\
\hline Non-Hispanic black & $2(11)$ \\
\hline Hispanic white & $2(11)$ \\
\hline Asian & $1(6)$ \\
\hline \multicolumn{2}{|l|}{ Employment (self-report) } \\
\hline Retired & $4(22)$ \\
\hline Disabled & $2(11)$ \\
\hline Medical leave & $1(6)$ \\
\hline Unemployed & $4(22)$ \\
\hline Homemaker & $2(11)$ \\
\hline Employed <32 h/week & $1(6)$ \\
\hline Employed $>32 \mathrm{~h} /$ week & $4(22)$ \\
\hline \multicolumn{2}{|l|}{ Insurance } \\
\hline Managed care & $3(17)$ \\
\hline Dual Medicare+Medicaid & $1(6)$ \\
\hline Medicare & $5(28)$ \\
\hline Medicaid & $6(33)$ \\
\hline Commercial & $3(17)$ \\
\hline \multicolumn{2}{|l|}{ Educational attainment } \\
\hline$<$ High school diploma & $2(11)$ \\
\hline Some college/junior college & $4(22)$ \\
\hline College graduate & $6(33)$ \\
\hline Advanced degree & $6(33)$ \\
\hline \multicolumn{2}{|l|}{ Marital status } \\
\hline Married & $13(72)$ \\
\hline Never married/divorced/single/widow & $5(28)$ \\
\hline \multicolumn{2}{|l|}{ Household financial situation } \\
\hline $\begin{array}{l}\text { After paying bills, have money } \\
\text { for special things you want }\end{array}$ & $9(50)$ \\
\hline $\begin{array}{l}\text { Enough money for bills, little spare money } \\
\text { to buy extra or special things }\end{array}$ & $3(17)$ \\
\hline $\begin{array}{l}\text { Enough money for bills but only } \\
\text { with cutting back on things }\end{array}$ & $2(11)$ \\
\hline Difficulty paying bills, no matter what & $4(22)$ \\
\hline \multicolumn{2}{|l|}{ Surgery } \\
\hline Not recommended & $1(6)$ \\
\hline Lumpectomy & $8(44)$ \\
\hline Mastectomy & $6(33)$ \\
\hline Bilateral mastectomy & $3(17)$ \\
\hline \multicolumn{2}{|l|}{ Radiation } \\
\hline Not recommended & 7 (39) \\
\hline Recommended but not initiated & $0(0)$ \\
\hline Received & $11(61)$ \\
\hline \multicolumn{2}{|l|}{ Chemotherapy } \\
\hline Not recommended & $4(22)$ \\
\hline Recommended but not initiated & $1(6)$ \\
\hline Received & $13(72)$ \\
\hline \multicolumn{2}{|l|}{ Hormonal therapy } \\
\hline Not recommended & $3(17)$ \\
\hline Recommended but not initiated & $1(6)$ \\
\hline Received & $14(78)$ \\
\hline
\end{tabular}

1 woman with metastatic disease was not recommended for surgery. Fourteen of 17 women having surgery reported no major problems with their procedures; 3 women reported having postoperative complications, lymphedema, or infection.

Radiation. Eleven women were recommended for and received radiation. Ten (of 11) women reported that the 


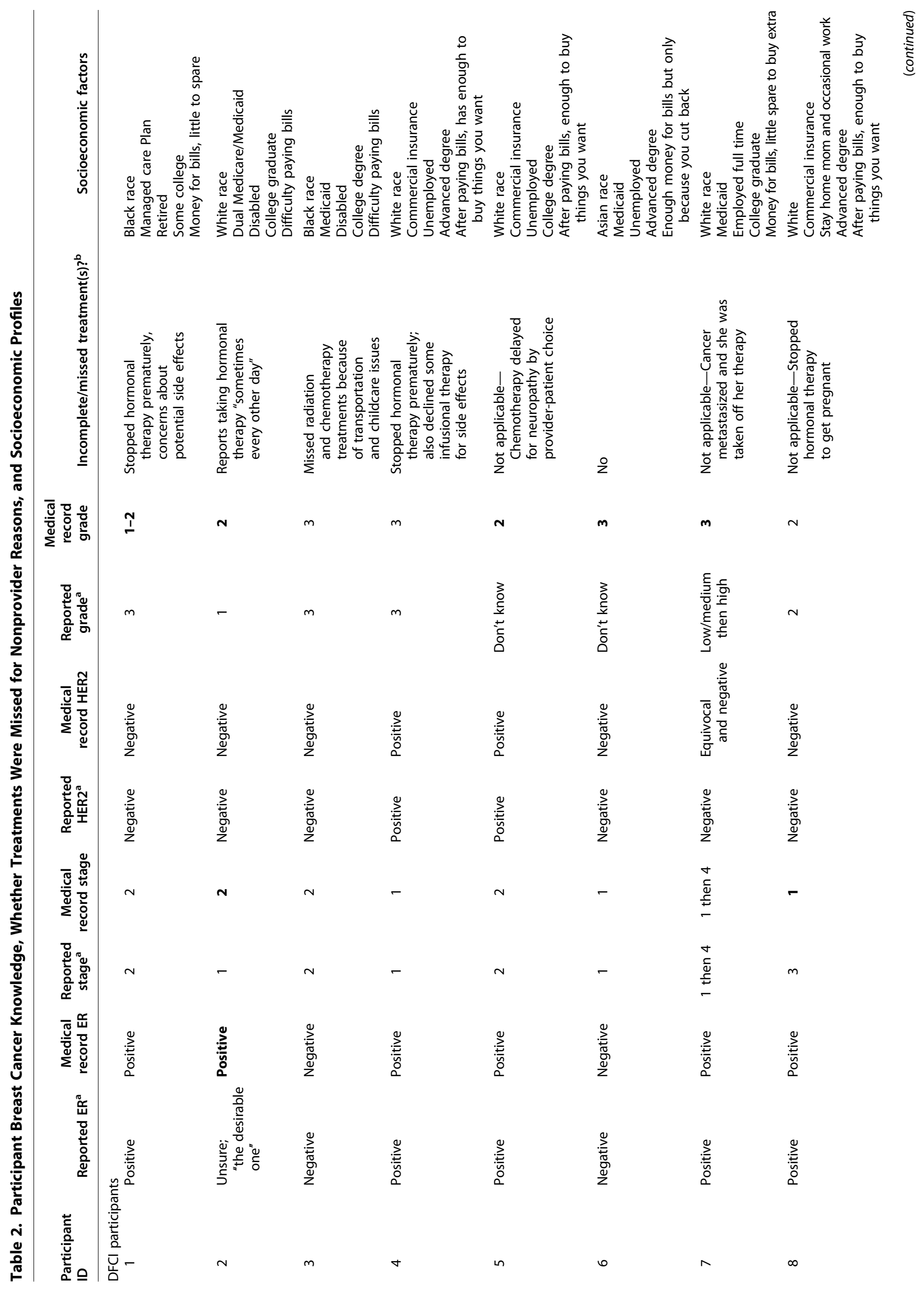









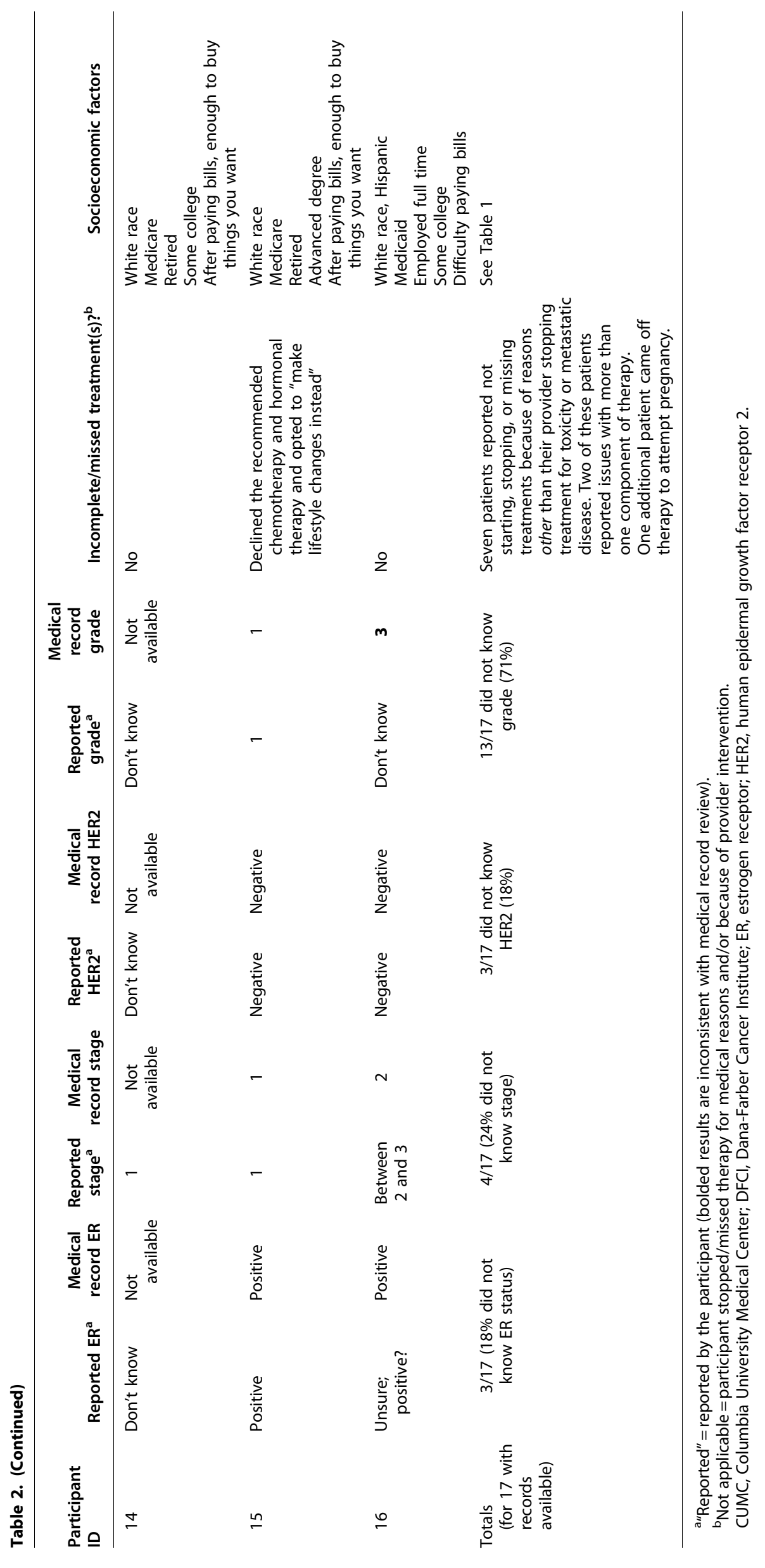


rationale for radiation was to eliminate remaining cancer cells, for example, "Um, ...So the one thing I DO remember is that, even after the excision, there were some questionable cells. Uh...I believe they were pre-cancer, um, and that they felt the, um...radiation would take care of those." Another participant reported: "the surgery took care of the cancer, and this is more like an insurance policy..." Three women reported that a reduction in recurrence was their primary goal for radiation, for example, "...after chemo, radiation was a, a next step to ensuring that it wouldn't come back." And another participant: "...the bottom line is that the radiation, uh, reduced the...chance of recurrence in half..." Seven of 11 women who had radiation reported no problems with treatment; 3 reported side effects/complications (fatigue/exhaustion $[n=2]$, "major inflammation" $[n=1])$ and 1 reported technical issues with the radiation equipment.

With regard to the reasons for missing radiation treatments, three women reported having missed treatments because of transportation ("I did [miss treatments]... Transportation, childcare. I didn't miss too many...but I did have some issues with... The Ride? [transportation service for disabled patients]...Sometimes drivers don't show up...") and one woman did not want to continue treatment:"Uh, I completed it up, except for the last three days...but my family members urged me to complete it, and I did... I was, very tired of having treatment...I mean, although radiation didn't have a huge amount of side effects....but, my family said, 'You've come so far, you know, uh, why cut it out?' So, I came back and...we were able to finish it up."

Chemotherapy. Chemotherapy was recommended for 14 participants, with 13 receiving it and 1 declining treatment. Twelve of the 13 participants receiving chemotherapy expressed awareness about the goals of the chemotherapy as explained by their clinical team. These were categorized as the following (and not mutually exclusive): (1) to shrink the cancer $[n=6],(2)$ to prepare for surgery/make surgery easier $[n=5],(3)$ to kill/attack/ eradicate the cancer $[n=6],(4)$ to treat with chemotherapy after other failed treatments $[n=3]$, and (5) other $[n=1]$. Relevant excerpts include the following: "we had to do chemo to shrink it," and "they wanted to shrink the tumor," and "...I believe the combination of drugs were to attack different stages of cell... cell growth? But that's all I remember," and "So I don't have breast cancer in other places in my body."

The one participant who declined recommended chemotherapy (Table 2) reported declining treatment because of research she did online to better understand her diagnosis. She stated (paraphrased because of length of response) that while her doctors did an excellent job of explaining the benefits of chemotherapy, as a result of her own research, she opted to make lifestyle changes instead. For the 13 participants who started chemotherapy, 6 reported missing treatments, 4 of them due to side effects ( 3 never returned to treatment, 1 had a delay for neutropenia but completed treatment) and 2 because of logistical issues (childcare and transportation). Both participants reporting logistical issues were the same women who reported missing radiation treatments for similar reasons. It is not clear if these two women completed all of their chemotherapy.

Twelve of the 13 participants receiving chemotherapy discussed having some difficulties with treatment, categorized (and not mutually exclusive) as side effects $(n=11)$ and treatments "not working" ( $n=2$ for those with metastatic disease). The side effects reported as problematic with chemotherapy included fatigue $(n=6)$, alopecia $(n=5)$, nausea $(n=5)$, neuropathy $(n=5)$, diarrhea $(n=2)$, muscle pain/aches $(n=3)$, fever/other illness $(n=2)$, feeling lousy/not themselves $(n=3)$, epistaxis $(n=1)$, and weight loss $(n=1)$. The three women stopping chemotherapy early (and not returning to treatment) because of side effects were among those reporting neuropathy. One of these three women also noted weakness, alopecia, and nausea (although she stated: "[I had] the normal...fatigue, hair loss, nausea, that sort of thing, but my big, long-standing issue is the neuropathy."). Eight women qualified/normalized some of their side effects, suggesting that the problems they experienced were expected, tolerable, or not as bad as they anticipated, "I have medicine for nausea, so, I'm ok with the nausea" or "For me, it wasn't as bad as for other people that I have heard has been terrible..." Overall, 3 of 13 women reported requiring dose reductions in their chemotherapy during their treatment because of side effects but only one of these women did not complete her treatment.

Hormonal therapy. Fifteen of 18 women reported being recommended for and had started hormonal therapy; 1 did not initiate hormonal therapy (Table 2). Two women did not know why they were prescribed these medications, for example, "I really don't remember. I was just so happy to take one pill a day. I could do this!" The remaining women reported knowing the rationale for treatment and provided the following rationales: because of their hormone receptor status $(n=5)$, 
to prevent recurrence $(n=4)$, to be put into menopause $(n=4)$, because of genetic factors $(n=2)$, and because her clinical trial had an added treatment as a way to help treat their cancer $(n=1)$.

For the women recommended for hormonal therapy $(n=15)$, one patient declined therapy initiation and was the same patient who declined chemotherapy ("...I chose to make some lifestyle changes instead of taking a drug...the [side effects] are daunting...And...I just wasn't about to put myself in, you know, side effects for more than I wanted to endure...I couldn't see the advantage"). Of the 14 women who initiated treatment, 3 reported making a mistake with their pill regimen but all 3 reported getting back on track quickly (and were not categorized as nonadherent for these reasons because they reported a few missed doses). For example:"I would miss one, just for forgetfulness, but I got myself a pill box and I got a lot better at it" (this patient also stopped treatment prematurely to attempt pregnancy). One woman reported taking her hormonal therapy every other day to combat side effects, and six women reported stopping their medications because of personal concerns about potential side effects $(n=1)$, side effects experienced after 3 months of therapy without agreeing to try alternatives $(n=1)$, to become pregnant $(n=1)$, because of cancer recurrence $(n=1)$, to switch hormonal therapies $(n=1)$, and due to low blood counts while on a clinical trial $(n=1)$.

Comments from the two women concerned about side effects include: "...I stopped taking it because, um, I had a concern about some of the side effects of taking tamoxifen...you know the aneurism, blood clots, and...I just felt really uncomfortable with that? And so I take... 'Reliv', which is a micronutrient, and...it's natural...I know people who have taken tamoxifen..and their breast cancer metastasized...And so, I just felt like...why should I take something that has risks, that can cause cancer in other parts of my body. There's no...sure way that, you know, it WON'T metastasize. I know people...that it actually DID metastasize, AFTER they took the Tamoxifen." And another participant: "I tried tamoxifen for approximately three months, and...the side effects were such that...I was very concerned about my quality of life and my ability to be mobile and active...So, I just stopped."

\section{Breast cancer knowledge}

Among the 17 with medical records available, breast cancer knowledge about one's own cancer was variable (Table 2). Most women correctly reported their cancer stage (76\%), ER status (82\%), and human epidermal growth factor receptor 2 (HER2) status (82\%), although fewer women $(29 \%)$ knew their tumor grade. One woman who reported missing both radiation and chemotherapy treatments because of transportation issues did not know any tumor characteristics; another who missed some radiation treatments did not know her cancer stage. One additional woman who prematurely stopped hormonal therapy reported incorrect grade. Two other women who stopped hormonal therapy reported correct tumor characteristics for all elicited information. The one woman without medical record data available did not know three of the four tumor characteristics.

\section{Reasons for completing treatment}

Twelve women reporting finishing all of their recommended treatments, reporting various motivations for this, with recommendations made by doctors serving as the most common reason $(n=6)$. Representative comments include: "I trust my providers," "I've always been very proactive, as far as my care," and "If they recommend...who am I to argue with that?" Three women expressed "wanting to live" as their main motivation to complete treatment. Other participants identified their own personal approach/attitude $(n=5)$, wanting to prevent recurrence $(n=3)$, and children $(n=3)$ as motivating forces.

\section{Discussion}

This qualitative study of a diverse sample of women with breast cancer in Boston and New York sought to understand better the intersection of breast cancer knowledge, treatment rationales, and receipt of incomplete treatments. Our results point to the complex, diverse, and dynamic experiences and treatment barriers that exist. In addition to chemotherapy toxicity requiring dose interruption or modification, a substantial proportion of women ( $\approx 39 \%$ ) reported logistical (transportation, childcare) or personal preference barriers that limited their compliance. Nearly all women accurately reported treatment rationales, although some did not know their breast cancer subtype and stage, and most did not know their tumor grade. While we did not observe a clear association between knowledge about one's own breast cancer and specific treatment rationales with treatment receipt and treatment completion, some women with inadequate knowledge about their disease did not complete treatment.

Existing research suggests that general cancer knowledge is poor overall, ${ }^{18-20}$ and breast cancer patients report wanting more information from their providers. ${ }^{21}$ In one study, on average, breast cancer patients correctly answered 7/10 
true-or-false general breast cancer knowledge questions (e.g., equivalent long-term survival for lumpectomy and mastectomy). ${ }^{19}$ The impact of general cancer knowledge or understanding of one's own cancer on receipt of cancer treatments is limited, although studies suggest associations of knowledge and education about cancer with receipt of cancer screening. ${ }^{22-24}$ Furthermore, general cancer knowledge is associated with earlier stage at presentation and survival, ${ }^{10,11}$ as well as enhanced satisfaction with cancer care. $^{18,25,26}$

In turn, it is plausible that an improved understanding of one's breast cancer and the reasons that treatments are recommended might increase rates of treatment initiation and adherence. There are preliminary suggestions to support this, including our prior work in a survey of women with breast cancer in California ${ }^{13}$ and qualitative studies. $^{18,27}$ One qualitative study of 49 black breast cancer patients found that many lacked knowledge about their diagnosis and treatments, and those with a better understanding more often adhered to treatments. ${ }^{27}$ Our study lends further evidence that one's knowledge about her own disease can be improved upon. Although many factors contribute to disparities, improving breast cancer knowledge and understanding of disease are modifiable and may impact adherence to care. Improving cancer knowledge and knowledge about one's own disease may also impact a woman's trust, communication, confidence, and satisfaction with her treatment team. The relationship between knowledge and treatment receipt and outcomes should be explored further in the context of a larger study; such work is planned by our study team in a larger scale, multicenter survey study.

There is increasing attention to the development of novel interventions to improve treatment completion and adherence. Because reasons for nonadherence to treatment recommendations are complex and include patient, provider, and institutional factors, a one-size-fits-all solution is unlikely to be effective. Instead, a more individualized approach to overcoming barriers, many of which are addressable and were discussed by women in our study (i.e., childcare, reliable transportation, education around importance of treatment), may be worth evaluating. Our findings suggest that these logistical barriers may substantially contribute to disparities in care and treatment completion. Studies have cited that interventions aimed to address depression, ${ }^{28}$ communication, ${ }^{29}$ and awareness of treatment effects on fertility ${ }^{30}$ may help promote adherence to hormonal therapy in particular. Others have recently suggested that out-ofpocket expense and subsidies for hormonal therapy may also have a large impact on adherence. ${ }^{31,32}$ In addition, studies have emphasized the value of patient navigation not just in screening but also in cancer populations. ${ }^{33-38}$ Patient navigation remains a promising and active area of study and clinical implementation with additional results in cancer populations forthcoming. It is of note that one small study which performed a patient needs assessment to tailor assistance failed to improve receipt of adjuvant treatment, although this study had high rates of adjuvant treatment receipt for all women. ${ }^{39}$

We acknowledge multiple study limitations. We enrolled 18 patients from only two academic medical centers and it was not possible to enroll only women who were nonadherent with their treatments, although we let DFCI providers know we were interested in such patients. As a result, the proportion of patients who did not complete (or had interrupted) treatment may not be generalizable to the overall breast cancer population. Second, because of the exploratory nature of our study, we could not formally assess associations of breast cancer knowledge with treatment receipt. Finally, our study included a one-time interview, a few years after diagnosis for some women, which may have resulted in recall bias about treatments received, knowledge, and reasons for cessation/nonadherence.

\section{Conclusions}

In conclusion, in this socioeconomically diverse group of patients, we identified a significant proportion of women who did not complete care as recommended and were forthright about the logistical and potential knowledge barriers to treatment they experienced. Additional qualitative and quantitative studies are needed regarding how to optimally deliver cancer care in a tailored and personalized approach that addresses each patient's needs and vulnerabilities. Patients facing challenges with treatment continuation or completion need to be asked what these challenges are and clinicians need to work with them to find solutions.

\section{Acknowledgments}

American Cancer Society (R.A.F.; 125912-MRSG-14-24001-CPPB), Susan G. Komen (R.A.F.; CCR14298143), and National Cancer Institute (N.L.K.; K24CA181510). The authors thank all patients who participated.

\section{Author Disclosure Statement}

No competing financial interests exist.

\section{References}

1. SEER Cancer Statistics Review, 1997-2007. 5-Year relative survival (percent) 1999-2006 by age at diagnosis. http://seer.cancer.gov/csr/ 1975_2007/browse_csr.php?section=4\&page=sect_04_table. 14.html\#table 4 Accessed March 11, 2011. 
2. Jatoi I, Anderson WF, Rao SR, et al. Breast cancer trends among black and white women in the United States. J Clin Oncol. 2005;23:7836-7841.

3. Haggstrom DA, Quale C, Smith-Bindman R. Differences in the quality of breast cancer care among vulnerable populations. Cancer. 2005;104:2347-2358.

4. Bickell NA, Wang JJ, Oluwole S, et al. Missed opportunities: racial disparities in adjuvant breast cancer treatment. J Clin Oncol. 2006:24:1357-1362.

5. Du XL, Lin CC, Johnson NJ, et al. Effects of individual-level socioeconomic factors on racial disparities in cancer treatment and survival: findings from the National Longitudinal Mortality Study, 1979-2003. Cancer. 2011; 117:3242-3251.

6. Partridge $A H$, Hughes ME, Warner ET, et al. Subtype-dependent relationship between young age at diagnosis and breast cancer survival. J Clin Oncol. 2016;34:3308-3314.

7. Chen $\mathrm{HL}$, Zhou MQ, Tian W, et al. Effect of age on breast cancer patient prognoses: a population-based study using the SEER 18 database. PLoS One. 2016;11:e0165409.

8. Schonberg MA, Marcantonio ER, Li D, et al. Breast cancer among the oldest old: tumor characteristics, treatment choices, and survival. J Clin Oncol. 2010;28:2038-2045.

9. Freedman RA, Kouri EM, West DW, et al. Racial/ethnic disparities in knowledge about one's breast cancer characteristics. Cancer. 2015;121:724-732.

10. Goodwin JS, Samet JM, Hunt WC. Determinants of survival in older cancer patients. J Natl Cancer Inst. 1996;88:1031-1038.

11. Samet JM, Hunt WC, Goodwin JS. Determinants of cancer stage. A populationbased study of elderly New Mexicans. Cancer. 1990;66:1302-1307.

12. Bickell NA, Weidmann J, Fei K, et al. Underuse of breast cancer adjuvant treatment: patient knowledge, beliefs, and medical mistrust. J Clin Oncol. 2009;27:5160-5167.

13. Freedman RA, Kouri EM, West DW, et al. Association of breast cancer knowledge with receipt of guideline-recommended breast cancer treatment. J Oncol Pract. 2016;12:e613-e625.

14. Hershman DL, Shao T, Kushi LH, et al. Early discontinuation and non-adherence to adjuvant hormonal therapy are associated with increased mortality in women with breast cancer. Breast Cancer Res Treat. 2011;126:529-537.

15. Creswell JW. Qualitative Inquiry \& Research Design: Choosing Among Five Approaches, 3rd ed. Sage Publications: Thousand Oaks, CA, 2013.

16. Pope C, Ziebland S, Mays N. Qualitative research in health care. Analysing qualitative data. BMJ. 2000:320:114-116.

17. Richie JP, Spencer L. Qualitative data analysis for applied policy research In: The Qualitative Researchers Companion. Huberman AM, Miles MB (eds.) Sage Publications: London; 2002.

18. Fagerlin A, Lakhani I, Lantz PM, et al. An informed decision? Breast cancer patients and their knowledge about treatment. Patient Educ Couns. 2006; 64:303-312.

19. Chen JY, Diamant AL, Thind A, et al. Determinants of breast cancer knowledge among newly diagnosed, low-income, medically underserved women with breast cancer. Cancer. 2008;112:1153-1161.

20. Lukwago SN, Kreuter MW, Holt CL, et al. Sociocultural correlates of breast cancer knowledge and screening in urban African American women. Am J Public Health. 2003:93:1271-1274.

21. von Friederichs-Fitzwater MM, Denyse T. The unmet needs of AfricanAmerican women with breast cancer. Adv Breast Cancer Res. 2012;1:1-6.

22. Boling W, Laufman L, Lynch GR, et al. Increasing mammography screening through inpatient education. J Cancer Educ. 2005:20:247-250.

23. Kessler TA. Increasing mammography and cervical cancer knowledge and screening behaviors with an educational program. Oncol Nurs Forum. 2012;39:61-68.

24. Sabatino SA, Lawrence B, Elder $R$, et al. Effectiveness of interventions to increase screening for breast, cervical, and colorectal cancers: nine updated systematic reviews for the guide to community preventive services. Am J Prev Med. 2012;43:97-118.

25. Fallowfield LJ. Treatment decision-making in breast cancer: the patientdoctor relationship. Breast Cancer Res Treat. 2008;112 Suppl 1:5-13.

26. Street RL, Jr., Voigt B. Patient participation in deciding breast cancer treatment and subsequent quality of life. Med Decis Making. 1997;17:298-306.

27. Sheppard VB, Adams IF, Lamdan R, et al. The role of patient-provider communication for black women making decisions about breast cancer treatment. Psychooncology. 2011;20:1309-1316.

28. Mausbach BT, Schwab RB, Irwin SA. Depression as a predictor of adherence to adjuvant endocrine therapy (AET) in women with breast cancer: a systematic review and meta-analysis. Breast Cancer Res Treat. 2015;152:239-246.
29. Farias AJ, Ornelas IJ, Hohl SD, et al. Exploring the role of physician communication about adjuvant endocrine therapy among breast cancer patients on active treatment: a qualitative analysis. Support Care Cancer. 2017:25:75-83.

30. Benedict C, Thom B, Teplinsky E, et al. Family-building after breast cancer: considering the effect on adherence to adjuvant endocrine therapy. Clin Breast Cancer. 2017;17:165-170.

31. Farias AJ, Du XL. Association between out-of-pocket costs, race/ethnicity, and adjuvant endocrine therapy adherence among Medicare patients with breast cancer. J Clin Oncol. 2017;35:86-95.

32. Biggers A, Shi Y, Charlson J, et al. Medicare $D$ subsidies and racial disparities in persistence and adherence with hormonal therapy. J Clin Oncol. 2016;34:4398-4404.

33. Ko NY, Darnell JS, Calhoun E, et al. Can patient navigation improve receipt of recommended breast cancer care? Evidence from the National Patient Navigation Research Program. J Clin Oncol. 2014;32:2758-2764.

34. Battaglia TA, Darnell JS, Ko N, et al. The impact of patient navigation on the delivery of diagnostic breast cancer care in the National Patient Navigation Research Program: a prospective meta-analysis. Breast Cancer Res Treat. 2016;158:523-534.

35. Freund KM. Implementation of evidence-based patient navigation programs. Acta Oncol. 2017;56:123-127.

36. Ko NY, Snyder FR, Raich PC, et al. Racial and ethnic differences in patient navigation: results from the Patient Navigation Research Program. Cancer. 2016;122:2715-2722.

37. Baik SH, Gallo LC, Wells KJ. Patient navigation in breast cancer treatment and survivorship: a systematic review. J Clin Oncol. 2016;34:3686-3696.

38. Carroll JK, Humiston SG, Meldrum SC, et al. Patients' experiences with navigation for cancer care. Patient Educ Couns. 2010;80:241-247.

39. Bickell NA, Geduld AN, Joseph KA, et al. Do community-based patient assistance programs affect the treatment and well-being of patients with breast cancer? J Oncol Pract. 2014;10:48-54.

Cite this article as: Freedman RA, Revette AC, Hershman DL, Silva $\mathrm{K}$, Sporn NJ, Gagne JJ, Kouri EM, Keating NL (2017) Understanding breast cancer knowledge and barriers to treatment adherence: a qualitative study among breast cancer survivors, BioResearch Open Access 6:1, 159-168, DOI: 10.1089/biores.2017.0028.

$\begin{aligned} & \text { Abbreviations Used } \\ & \mathrm{CUMC}=\text { Columbia University Medical Center } \\ & \mathrm{DFCl}=\text { Dana-Farber Cancer Institute } \\ & \mathrm{ER}=\text { estrogen receptor } \\ & \mathrm{HER} 2=\text { human epidermal growth factor receptor } 2 \\ & \mathrm{SES}=\text { socioeconomic status }\end{aligned}$

\section{Publish in BioResearch Open Access}

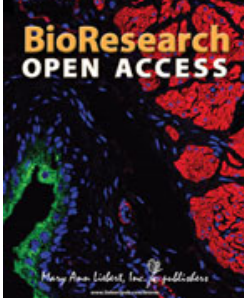

- Broad coverage of biomedical research - Immediate, unrestricted online access

- Rigorous peer review

- Compliance with open access mandates

- Authors retain copyright

- Highly indexed

- Targeted email marketing

\section{liebertpub.com/biores}

